\title{
SUBSÍDIOS PARA \\ IMPLANTAÇÃO DA EDUCAÇÃO AMBIENTAL NO PARQUE NACIONAL DE SETE CIDADES (PI) POR MEIO DA PERCEPÇÃO DOS MORADORES DE UMA COMUNIDADE DO ENTORNO
}

Toni Nhaga ${ }^{1}$

Maria de Fátima Camarotti ${ }^{2}$

Maria Luíza Dias Correia ${ }^{3}$

Resumo: Com o propósito de compreender a inter-relação dos moradores da zona de amortecimento do PNSC - Parque Nacional de Sete Cidades (PI) com os animais que vivem fora e dentro da Unidade de Conservação através da Educação Ambiental (EA), realizou-se uma investigação a partir das abordagens qualitativa e quantitativa. Os dados foram coletados utilizando entrevistas semiestruturadas com os moradores $(n=28)$ da comunidade de Cachoeira e interpretados através da técnica de análise de conteúdo. $O$ estudo concluiu que os moradores da região possuíam pouco conhecimento formal do conjunto de conteúdos que podem ser definidos como Consciência Ambiental. $\mathrm{E}$, a partir das ações desenvolvidas nesta pesquisa, a estruturação deste conhecimento foi ampliada, com destaque às discussões sobre a fauna local, sobretudo acerca dos animais considerados peçonhentos.

Palavras-chave: Percepção Ambiental; Biodiversidade Animal; Moradores da Zona de Amortecimento.

\footnotetext{
1 Universidade Federal da Paraíba. E-mail: nitonhaga@hotmail.com, Link para o Lattes: http://lattes.cnpq.br/7160166185205637

2Universidade Federal da Paraíba. E-mail: fcamarotti@yahoo.com.br. Link para o Lattes: http://lattes.cnpq.br/1578146214856644

3Universidade Federal da Paraíba. E-mail: maludiascorreiadc@hotmail.com. Link para o Lattes: http://lattes.cnpq.br/2636892805015227
} 
Abstract: An investigation was carried out based on qualitative and quantitative approaches with the objective of understanding the interrelationship between residents of the buffer zone of the PNSC - Sete Cidades National Park (PI, Brazil) with animals that live outside and inside the Conservation Unit through Environmental Education. The data were collected using semi-structured interviews with the residents $(n=28)$ of the Cachoeira community and interpreted using the content analysis technique. The study concluded that the residents of the region had little formal knowledge of the set of contents that can be defined as Environmental Awareness. And, based on the actions developed in this research, the structuring of this knowledge was expanded, with emphasis on discussions about the local fauna, especially about animals considered venomous.

Keywords: Environmental Perception; Animal Biodiversity; Residents of the Buffer Zone.

\section{Introdução}

Compreende-se a Percepção Ambiental como um processo que envolve vários elementos desde os sensoriais, subjetivos, valores sociais, culturais e atitudes ambientais das comunidades habitantes nas cidades em relação ao espaço natural e transformado, afirma Melazo (2005), enquanto Palma (2005, p.17) ratifica que,

[...]os seres humanos percebem através da visão, tato, olfato, paladar e audição. Como todos os seres humanos compartilham dos mesmos órgãos do sentido têm percepções comuns à espécie, podendo existir diferentes habilidades, conforme a sua cultura (PALMA, 2005, p.17).

No entanto, cada sociedade tem às suas próprias características instituídas na base de valores sociais e culturais que são edificadas através do pensamento humano. Logo, a Percepção Ambiental possui diferentes interpretações a depender da percepção do sujeito de acordo com o contexto cotidiano, criando e ampliando os significados, planificando a sua consciência em relação ao entorno, sobretudo a valorização do lugar, destino ou ambiente no qual se encontra. Toda sociedade organizada é regida a partir de valores sociais e culturais que permitem instituir regras para que o meio ambiente e a biodiversidade sejam respeitados.

No Brasil, a política ambiental teve maior desenvolvimento com a criação do Sistema de Nacional de Unidades de Conservação (SNUC), através da Lei № 9.985, de 18 de julho de 2000, que permitiu a criação das normas que direcionaram as ações do governo nas esferas federal, estadual e municipal (BRASIL, 2000). 
A Educação Ambiental (EA) faz parte de um processo que promove a integração entre as pessoas e as comunidades onde vivem, tornando-as participativas e críticas, promovendo mudanças de atitudes práticas, seja individualmente ou coletivamente, com o intuito de resgatar a integração entre as partes em prol do bem comum (ABíLIO, 2008).

Segundo Sato (2001), a EA é implementada através de estratégias de sensibilização com o intuito de provocar mudanças de comportamento, diferenciadas com diversos recursos como oficinas pedagógicas com vídeos e filmes, coleção de animais e histórias em quadrinhos visando criar estruturas que permitam ao indivíduo compreender melhor a importância da EA para a sensibilização do cidadão e torná-lo agente transformador, comprometido com o meio e o entorno, apropriando-se das causas ambientais como um todo.

Diante do contexto apresentado, as problemáticas centrais que se pretende responder com o presente estudo são: Qual é a Percepção Ambiental dos moradores da zona do amortecimento do Parque Nacional de Sete Cidades (PNSC), em relação aos animais que vivem dentro e fora do Parque? Quais são as ações de sensibilização do PNSC em relação à fauna dentro da Unidade de Conservação (UC) e no entorno? Nesta perspectiva, o presente artigo propôs as seguintes hipóteses: os residentes da zona de amortecimento do PNSC reconhecem os animais que vivem dentro e fora do PNSC por estarem localizadas em proximidade da UC; A EA, através do processo de sensibilização, possibilita entendimento entre os as pessoas que vivem no entorno sobre a fauna dentro da UC, permitindo-lhes compreender os benefícios dos serviços ecossistêmicos e a diminuição dos impactos ambientais negativos dentro e fora do PNSC.

A pesquisa teve como o objetivo compreender a inter-relação dos moradores da zona de amortecimento do PNSC nas cidades de Brasileira e Piracuruca, situadas no estado do Piauí, com os animais que vivem fora e dentro da Unidade de Conservação a partir dos conceitos da Percepção Ambiental. Este estudo, ainda, diagnosticou a Percepção Ambiental dos moradores da comunidade do entorno do PNSC em relação aos animais Vertebrados e Invertebrados da zona de amortecimento da Unidade de Conservação. Também foram averiguados quais são as ações de sensibilização do PNSC na comunidade de Cachoeira (município de Brasileira - Piauí) e, por último, iniciado um processo de sensibilização com as pessoas da comunidade do entorno do PNSC, através da EA, visando diminuir os impactos negativos na zona de amortecimento, de modo que a biodiversidade animal seja conservada.

\section{Material e métodos}

Utilizou-se os pressupostos teóricos metodológicos das abordagens qualitativa e quantitativa. A pesquisa qualitativa caracteriza-se como um conjunto de métodos para a compreensão detalhada dos significados e 
características situacionais apresentadas pelos entrevistados em lugar da produção de medidas quantitativas de características ou comportamentos (RICHARDSON et al., 2010).

Também foi aplicada a técnica de observação não participante com contato direto com a comunidade sem interferir, e vivenciar momentos como um elemento neutro, segundo Lakatos e Marconi (2010), e a observação participante, segundo Richardson et al. (2010), foi adotada com intuito de facilitar a interação com os moradores no momento das atividades das entrevistas e de sensibilização. Foram anotadas no diário de campo as percepções da comunidade referentes à importância da biodiversidade.

O estado do Piauí é conhecido como uma região muito quente, e, para Lima et al. (2011) o clima é definido, no norte do Estado Piauí, por duas estações, a chuvosa e a seca, com temperaturas anuais que variam de $26^{\circ} \mathrm{C}$ mínima e máxima de $34^{\circ} \mathrm{C}$, com precipitação média anual é de $1.400 \mathrm{~mm}$, e os maiores índices pluviométricos são concentrados entre os meses de janeiro e maio.

O decreto № 50.744, Art. 1ำ de 8 de junho de 1961 (BRASIL, 1961) criou, no Município de Piracuruca, no Estado do Piauí, o PNCS - Parque Nacional de Sete Cidades, que está subordinado atualmente ao ICMBio Instituto Chico Mendes de Conservação da Biodiversidade, mas antes era administrado pelo IBAMA - Instituto Brasileiro de Meio Ambiente.

O PNSC fica localizado entre os municípios de Piracuruca e Brasileira, latitude $04^{\circ} 05^{\prime} \mathrm{S}$ a $04^{\circ} 15^{\prime} \mathrm{S}$ e longitude $41^{\circ} 30^{\prime} \mathrm{W}$ a $41^{\circ} 45^{\prime} \mathrm{W}$, caracterizado pela vegetação de Cerrado e Caatinga, com eventuais matas ciliares e colônias de Buriti (Mauritia sp.) e Carnaúba (Copernica cerifera A. Mart) nas partes mais úmidas. No campo limpo, sobrepõe-se a arenização proveniente da destruição, pela erosão, dos arenitos (ROHDE, 2014). Ainda segundo o autor, a formação geológica do parque é constituída de rochas areníticas, o que se denomina de relevo ruiniforme. A altura das rochas varia de 3 a 20 metros e tem aproximadamente 20 quilômetros de extensão. Essa formação é Mesodevoniana (Devoniano Médio) e foi determinada, inicialmente, por estudos de pólens fósseis.

Favera (2002, p. 335) apresenta o PNSC como "um monumento natural magnífico, constituído de afloramentos rochosos de estratos do Devoniano na Bacia Sedimentar do Parnaíba" (Figura 1). 


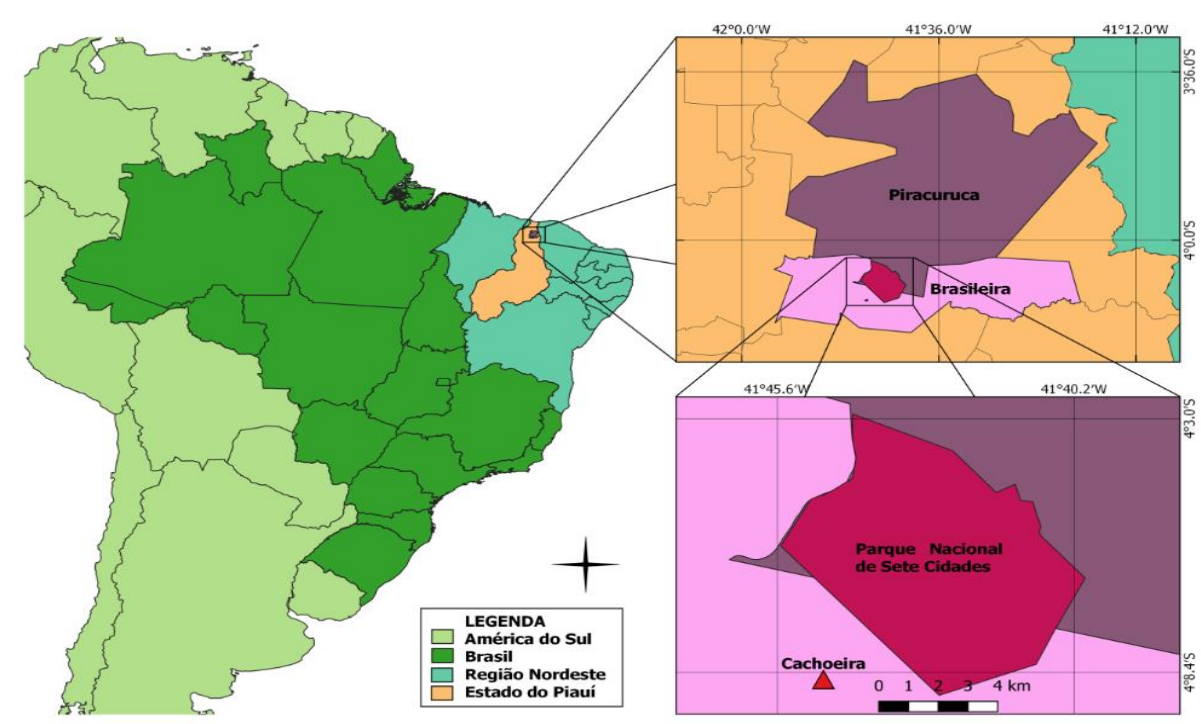

Figura 1: Localização da Comunidade de Cachoeira - Município de Brasileira Estado do Piauí e o Parque Nacional de Sete Cidades.

Fonte: Ferreira, 2019.

A coleta de dados foi realizada através de entrevistas semiestruturadas numa comunidade representada por uma população de 52 moradores distribuídos em 22 casas. Entretanto, foi necessário considerar somente os adultos com a idade a partir de 18 anos para a realização da pesquisa. Logo, as entrevistas foram realizadas com 28 moradores adultos da comunidade de Cachoeira.

Antes da coleta de dados o projeto foi enviado ao Comitê de Ética do Centro de Ciências Médicas (CCM) da Universidade Federal da Paraíba (UFPB) e aprovado em dezembro de 2018 sob o registro de número 3.089.940.

Os dados subjetivos colhidos foram interpretados a partir da técnica de análise de conteúdo, segundo Bardin (2016). Portanto, foi necessário realizar uma pré-análise das entrevistas transcritas, através da leitura flutuante, uma exploração exaustiva do material colhido e o tratamento dos resultados, através das inferências e interpretação com discussão baseada na literatura.

\section{Resultados e discussão}

\section{Dados demográficos dos moradores da comunidade de Cachoeira}

Foram entrevistados 28 moradores e, onde os homens representam $57,0 \%$ da população e as mulheres, $43,0 \%$. Quanto à faixa etária, $36,0 \%$ dos moradores têm idade entre 40 e 60 anos e $18,0 \%$ com a idade acima de 60 anos. Perante os dados contextualizados, compreende-se que há mais moradores predominantemente jovens do que os que se encontram na fase da terceira idade. 
$71,0 \%$ dos residentes são casados(as) e, os que são viúvos(as) representam $4,0 \%$. Logo, foi compreendido que prevalece a relação familiar entre os locais e, isso ficou bem explícito durante a coleta de dados em conversa informal, pois no momento da entrevista, perguntavam se já tinham sido entrevistados outros familiares que moravam nas casas próximas.

Percebeu-se também que ainda é presente o fenômeno de êxodo rural na comunidade de Cachoeira, pois muitos dos residentes se encontram na fase da terceira idade e, no decorrer da entrevista, alguns afirmavam que tinham vários filhos, e quando se perguntava por eles, respondiam que nenhum se encontrava na comunidade, pois haviam migrado para o sul ou sudeste do país.

Ainda, ressalta-se o impacto do êxodo rural no país, principalmente na região Nordeste, apesar de atualmente ser menos frequente que na década 1950. A região caracterizada pelas grandes limitações por ter o clima seco e pouco chuvoso e úmido, com temperaturas sempre altas e que, muitas vezes, dificultam a produção agrícola de subsistência desta região. No entanto, essas dificuldades puderam ser amenizadas a partir do uso de práticas agrícolas específicas como, por exemplo, agricultura de subsistência e agropecuária. Destacar que a região Nordeste concentra $47,8 \%$ da população rural do país, representando cerca de 14,3 milhões de pessoas (ALVES; SOUZA; MARRA, 2011).

O Nordeste brasileiro apresenta-se como uma vasta região em termos geográficos, econômicos, demográficos e é superpovoado, apesar da imagem que se faz nos centros mais desenvolvidos do país. Possui grande importância econômica e social, no entanto, ainda continua cicatrizado com problemas sociais, econômicos e ambientais, que podem ser compreendidos como uma consequência do processo da colonização, ao idealizar uma agricultura baseada na monocultura da cana-de-açúcar, causando empobrecimento do solo (DE SOUSA et al., 2017). Ainda para os autores, quando se fala do fenômeno da seca no Brasil, prontamente esta região é associada aos seguintes problemas: miséria, pobreza absoluta e secas periódicas.

Andrade (1993, p.18), considera,

A pobreza do Nordeste deriva-se, sobretudo da má distribuição da renda - há um forte contraste entre o nível de vida das classes dominantes e o povo - da grande concentração da propriedade fundiária, do sistema econômico nacional que transformou a região em fornecedora de matérias-primas e de mão-de-obra pouco qualificada para as regiões economicamente mais dinâmicas, e da apropriação das riquezas regionais por grupos econômicos internacionais e de outras áreas do país. 
Em relação à Renda Familiar, 53,0\% dos moradores tem renda abaixo de um salário-mínimo e, 11,0\% recebem mais de um salário. Entretanto, na zona de amortecimento do PNSC observou-se famílias em condições de pobreza que recebem ajuda do governo federal através do programa social Bolsa Família e com a adição da comercialização de produtos agrícolas que são produzidos por eles, ainda não é possível alcançar a renda mensal de um salário-mínimo.

Em relação à escolaridade, $25,0 \%$ dos moradores da comunidade é analfabeta e, os que estudaram até o 5a ano do Ensino Fundamental e Ensino Superior Completo, ambos representaram 4,0\% (este último, uma filha de uma moradora que se encontrava de férias na comunidade, formada em História).

Assim, com base na interpretação dos dados demográficos dos moradores percebeu-se que a comunidade vive numa situação de miséria, onde uma parte considerável vive com uma renda de menos de um saláriomínimo e enfrentando grandes dificuldades por serem ameaçados pela insegurança alimentar. Entretanto, a produção agrícola que se mantêm como principal fonte de renda dos moradores não tem uma maior rentabilidade por falta de um canal de distribuição mais estruturado para efetivar a comercialização dos produtos ou a própria comunidade não se organiza em criar uma cooperativa para escoamento dos produtos e, assim, valorizar mais a produção local.

\section{Respostas dos moradores sobre os animais}

Todos os moradores afirmaram que nunca usaram algum tipo de inseto para a alimentação. Porém, sabe-se que existe regiões do país nas quais há pessoas que usam insetos para fins alimentícios, por conta da proteína presente nesses animais. Para Teixeira Filho (2019) os insetos são vistos pela sociedade ocidental como animais nojentos e que são vetores de doenças, mas já há mudanças em relação a isto, como o uso de proteína de insetos de várias formas, seja como insetos fritos e/ou farinhas, que podem fazer parte de vários alimentos processados. Com isto, diversos criadores de insetos no Brasil organizaram, em 2018, a ASBRACI - Associação Brasileira dos Criadores de Insetos.

Os moradores, mesmo com baixa escolaridade, reconhecem que os insetos são importantes, pois fornecem alimento e protegem as plantas, mas também são perigosos (Quadro 1). 
Quadro 1: Respostas dos Moradores da Comunidade de Cachoeira. Município de Brasileira, PI.

\begin{tabular}{|c|c|c|c|}
\hline \multicolumn{3}{|c|}{ Qual a importância dos insetos para a vida das pessoas? } \\
\hline $\begin{array}{c}\text { São } \\
\text { importantes }\end{array}$ & $\begin{array}{c}\text { M1 - "Sim, eles são importantes, porque podemos nos } \\
\text { alimentar do mel das abelhas." } \\
\text { M5 - "Sim, eles são importantes para a cadeia alimentar." } \\
\text { M14 - "Eles são importantes, por exemplo: protegem e } \\
\text { ajudam no controle das pragas." }\end{array}$ & 14 & FA \\
\hline $\begin{array}{c}\text { São } \\
\text { perigosos }\end{array}$ & $\begin{array}{c}\text { M23 - "Eles não são importantes porque quando urinam } \\
\text { na gente, a gente queima." } \\
\text { M28 - "Não são importantes, porque eles picam a gente." }\end{array}$ & 7 & $25,0 \%$ \\
\hline $\begin{array}{c}\text { Não } \\
\text { souberam } \\
\text { responder }\end{array}$ & M15 - "Não soube dizer." perigosos." & 7 & $25,0 \%$ \\
\hline Total & & $\mathbf{2 8}$ & $\mathbf{1 0 0 , 0 \%}$ \\
\hline
\end{tabular}

Fonte: autoria própria (2019).

Os moradores usam o termo "inseto" de forma genérica e denominam os animais independentemente das espécies, sejam eles animais silvestres, sejam eles animais domésticos, com uma única nomenclatura, "os bichos", ou em outra linguagem "o que não presta". Nesta perspectiva, esta mesma nomenclatura generalista associada aos insetos de modo geral "os bichos", foi encontrada também por Costa Neto (2004). O autor salienta que "os seringueiros que vivem na Reserva Extrativista do Alto Juruá, no Acre, classificam como 'insetos' os bichos que picam com presas (como as cobras e morcegos), com ferrão (como a tocandira, tipo de formiga) ou com esporão (como as arraias)" (COSTA NETO, 2004, p, 59).

Destacam-se também substâncias venenosas existentes em grande variedade de espécies de insetos das ordens Hymenoptera, Hemiptera, Diptera, Coleoptera e Lepidoptera (COSTA NETO, 2004).

Ao trazer a mesma reflexão em relação aos residentes da comunidade de Cachoeira, isso pode ser compreendido pela falta da escolarização dos locais e, por outro lado, a falta de ações de sensibilização, através da EA, para as comunidades do entorno da UC em questão.

Entretanto, nas respostas das pessoas da comunidade de Cachoeira, observa-se que algumas faziam confusão para diferenciar os insetos das diferentes ordens como os insetos da Ordem Orthoptera: baratas, gafanhotos e grilos; Ordem Hymenoptera: abelhas, vespas, cupins e formigas; Ordem Coleoptera: besouros, joaninhas; Ordem Diptera: moscas, mosquitos e Ordem Lepidoptera: borboletas e mariposas (GALLO et al., 2002).

Os moradores citaram o tatu como um animal frequentemente visto e encontrado no PNSC, representando a maior frequência com $26,0 \%$ e, entre os menos citados, a arara azul chamou atenção com 4,0\%, uma das espécies ameaçadas de extinção devido à caça ilegal dos animais silvestres e tráfico das aves que ocorrem em todo o país. No entanto, de acordo com o Livro Vermelho 
da Fauna Brasileira Ameaçada de Extinção do MMA/ICMBio (2018), a Araraazul-grande (Anodorhynchus hyacinthinus), foi favorecida por ações de conservação, especialmente na região do Pantanal, beneficiada por acordos internacionais relacionados à atividade pesqueira, contribuiu expressivamente na recuperação dessa espécie de ave que saiu da lista dos ameaçados de extinção e teve uma mudança genuína em situação de conservação.

Logo, podemos considerar que a espécie de ave citada pelos moradores seja a Ararinha-azul-pequena (Anodorhynchus glaucus), esta sim, encontra-se na lista avaliada como extinta (EX) e foi categorizada como Regionalmente Extinta (RE), uma vez que só está extinta em território nacional (ICMBio, 2018). Porém, tem-se conhecimento que o habitat dessa espécie não é nesta zona de UC, apesar de ser um bioma com características de caatinga, similar ao habitat natural da Ararinha-azul-pequena (Anodorhynchus glaucus). Entretanto, a arara azul foi citada por alguns entrevistados como tipo de animal silvestre que costuma ser encontrado no PNSC, informação essa que pode passar de forma despercebida por alguns residentes.

Uma parte considerável das pessoas afirma que todos os animais devem ser protegidos, porém o tatu foi o animal mais citado, representando $32,0 \%$ e, em seguida, o veado com $19,0 \%$.

Sobre o meio ambiente, os moradores ressaltaram que é o "lugar em que se vive", como ressaltado por Sauvé (2005) nas tipologias. Os demais afirmaram que o meio ambiente seria "natureza" e, neste caso, apontaram os meios bióticos e abióticos que a compõem. Um morador (M18) reconheceu o meio ambiente como importante para todos e a enquadrou na tipologia de "biosfera" de Sauvé (2005). Observa-se que os locais fazem confusão entre os conceitos de "meio ambiente" e "Educação Ambiental", não conseguindo distinguir os dois termos e, dessa forma, $39,0 \%$ dos entrevistados não souberam responder à pergunta (Quadro 2).

Quadro 2: As respostas dos Moradores da Comunidade Cachoeira - Município de Brasileira, $\mathrm{PI}$, em relação à pergunta $\mathbf{O}$ que é meio ambiente na sua opinião? de acordo com as tipologias de Sauvé (2005).

\begin{tabular}{|c|c|}
\hline Unidade de contexto & Unidade de registro \\
\hline Lugar em que se vive & $\mathrm{M} 9$ - "É tudo que está no nosso redor [...]" \\
\hline Natureza & $\mathrm{M} 3$ - "Árvore que faz parte da natureza." \\
& $\mathrm{M} 6$ - "As árvores, rios e terras." \\
& $\mathrm{M} 12$ - "Fauna do mundo em geral." \\
& $\mathrm{M} 17$ - "Onde os seres vivos vivem e preciso conservar." \\
\hline Biosfera & M18 - "É importante, convivência de todos." \\
\hline
\end{tabular}

Fonte: autoria própria (2019).

A mesma quantidade de moradores afirmou que não sabia responder o que é "meio ambiente", portanto, pode-se compreender que talvez não seja um termo utilizado no cotidiano e, por isso, não foi fácil responder. 
A maior parte dos moradores da comunidade de Cachoeira, afirmou que a natureza é composta por tudo que está ao redor do PNSC, ou seja, árvores, pássaros, animais terrestres e plantas em geral. Para Tamaio (2002), essas respostas têm a ver com a tipologia naturalista, que engloba a natureza para ser apreciada e preservada. Em relação à resposta do M18 "Serve para cultivar feijão e milho", o meio ambiente serve para ser utilizado pelos seres humanos, se enquadrando na concepção antropocêntrica e para os moradores M1 e M19, a natureza tem uma visão romântica (Quadro 3).

Quadro 3: As respostas dos Moradores da Comunidade de Cachoeira Município de Brasileira, $\mathrm{PI}$, em relação à questão $\mathbf{O}$ que é Natureza? a partir das tipologias de Tamaio (2002)

\begin{tabular}{|c|c|}
\hline Categorias & Unidade de registro \\
\hline Antropocêntrica & M18 - "Serve para cultivar feijão e milho." \\
\hline \multirow{2}{*}{ Naturalista } & M20 - "Florestas, rios, rochas, os animais e as aves." \\
& M5-“São as árvores, os pássaros e os animais." \\
M7- "As plantas, tudo verde."
\end{tabular}

Fonte: autoria própria (2019).

Em relação à resposta dos entrevistados, 32,0\% afirmaram que a natureza serve para cultivar feijão e milho, ou seja, os serviços ecossistêmicos são prestados para a sociedade através do meio ambiente, entretanto, no entendimento dos locais, de todas as formas, a natureza é compreendida como elemento do meio ambiente, pois os mesmos não se incluem na biodiversidade das espécies que compõem este meio.

Segundo Abílio (2011), a EA é um processo interativo com duas vias que surge para mudar valores, atitudes e, consequentemente, práticas individuais e convívio coletivo. Dessa forma, as respostas foram interpretadas com base nas concepções e categorias do mesmo autor, e, demonstraram um conhecimento generalista, mas mesmo assim, alguns moradores mostraram que já foram sensibilizados, mesmo que parcialmente, já que só falaram em relação ao lixo (Quadro 4).

Quadro 4: As respostas dos moradores da comunidade de Cachoeira - Município de Brasileira, $\mathrm{Pl}$, segundo as concepções e categorias de Abílio (2011).

\begin{tabular}{|c|c|}
\hline \multicolumn{2}{|c|}{ Você já ouviu falar da Educação Ambiental? } \\
\hline Categorias & Unidades de Registro \\
\hline Generalista & M2 - "Sim, respeito à natureza e valorizar animais e plantas." \\
& M9 - "Educar para sobreviver." \\
\hline Preservacionista & M12 - "Limpar a natureza e preservar." \\
\hline Sensibilização & M13 - "Sim, é cuidar dos lixos, resíduos sólidos." \\
M14 - "Sim, é sobre a limpeza." \\
\hline $\begin{array}{c}\text { Não souberam } \\
\text { responder }\end{array}$ \\
M16 - "Já, mas não sei o que é." \\
M20 - "Não sei dizer, mas já ouvi falar." \\
M23 - "Não, nunca ouvi falar."
\end{tabular}

Fonte: autoria própria (2019). 
É importante realçar o papel da comunicação dentro e fora da UC que sempre deve ser mantida ativa por parte dos envolvidos (moradores do entorno e representantes da UC) e, quando falta esse elemento essencial, há um impacto negativo nas realizações das atividades de sensibilização através da EA, o que afeta diretamente a segurança e proteção da UC. Consequentemente, a fauna e a flora do parque ficam vulneráveis.

Assim, o processo da EA, através das ações de sensibilização (SATO, 2001), pode permitir a mudança de atitude dos moradores da comunidade rural da zona de amortecimento do PNSC sobre a relevância de proteger os animais, inclusive os que são ameaçados de extinção, dentro e fora da UC, assim, as futuras gerações poderão conhecê-los.

Quanto à Percepção Ambiental, os moradores foram unânimes em respostas, apenas um que afirmou que já tinha ouvido falar neste termo, porém não lembrava o que significava. Cerca de $97,0 \%$ dos moradores da comunidade não souberam responder. No entanto, quando o indivíduo compreende o ambiente, o que faz a partir da concepção e dimensão, distingue o entorno e pode desenvolver habilidades com vistas a modificar as atitudes, aumentando consciência ambiental, almejando, desse modo, a prevenção e a solução dos problemas ambientais (PEREIRA et al., 2014). Ainda os autores afirmam que é preciso reconhecer que este é um processo que se constrói a partir da realidade percebida pelo sujeito, portanto, cheia de subjetividades, o que requer a incorporação permanente de mecanismos formativos e informativos (PEREIRA et al., 2014). Percebe-se que os moradores não compreenderam a pergunta e isto pode estar relacionado ao nível de escolaridade baixo e por não estarem integrados ao ambiente no qual estão inseridos.

\section{Vivências sensibilizadoras com os moradores da comunidade de Cachoeira, PI}

Os moradores tinham pouca Percepção Ambiental. Após as vivências sensibilizadoras realizadas junto aos moradores da comunidade de Cachoeira, foi observado um aumento no conhecimento sobre a fauna (vertebrados e invertebrados) da região, destacando a importância da existência do PNSC e a influência desta instituição na preservação dos recursos naturais e geração de emprego e renda na região.

Portanto, os residentes foram convidados para participar das atividades de sensibilização que ocorreram no centro comunitário no qual funcionava também o posto de saúde. As ações de sensibilização e a escolha das atividades foram realizadas durante os diálogos com os moradores na comunidade de Cachoeira, com a participação dos adultos e crianças. Durante as apresentações de vídeos didáticos, as dúvidas eram esclarecidas quando algum ponto do vídeo não era compreendido. As atividades foram realizadas em dois dias. No primeiro dia foram ofertadas a $1^{\underline{a}}$ e $2^{\underline{a}}$ atividades e $1^{\underline{a}}$ oficina, 
com a participação de dez moradores, sendo que sete deles são adultos e três são crianças. Já no segundo dia, foram aplicadas a $3^{\mathfrak{a}}$ atividade e $2^{\underline{a}}$ oficina. As atividades atraíram mais crianças porque os adultos perceberam que as crianças tinham curiosidade e interesse em participar. O encontro foi proveitoso porque através das crianças pôde-se atingir o objetivo que era compartilhar a sensibilização de EA na comunidade. O número de participantes das atividades dobrou para 20 pessoas (sendo dez adultos e dez crianças). A disponibilidade dos residentes da comunidade reduziu o tempo planejado para as ações de cindo dias para dois dias (Quadro 5).

Quadro 5: Vivências realizadas com os moradores da Comunidade de Cachoeira localizada no Município de Brasileira, PI, em fevereiro de 2019.

\begin{tabular}{|c|c|c|c|}
\hline \multirow{4}{*}{$1^{\circ} \mathrm{dia}$} & Vivências & Objetivos & Descrição das atividades e oficinas \\
\hline & $\begin{array}{l}\text { 19 Atividade: vídeo - } 1 \\
\text { "Projeto Pró-Espécies } \\
\text { como iniciativa do } \\
\text { Ministério do Meio } \\
\text { Ambiente - MMA em } \\
\text { prol de espécies". }\end{array}$ & $\begin{array}{l}\text { Conhecer a } \\
\text { diversidade }\end{array}$ & \multirow{2}{*}{$\begin{array}{c}\text { Os dois vídeos foram apresentados } \\
\text { com o propósito de sensibilizar os } \\
\text { moradores sobre os vícios de } \\
\text { hiperconsumo acelerado do ser } \\
\text { humano e suas consequências e } \\
\text { sobre a caça predadora e o } \\
\text { desmatamento, com discussão ao } \\
\text { final. }\end{array}$} \\
\hline & $\begin{array}{l}\text { 2a Atividade: vídeo - } 2 \\
\text { "MAN by Steven Cutts - } \\
500,000 \text { anos atrás". }\end{array}$ & $\begin{array}{l}\text { Perceber as } \\
\text { consequências } \\
\text { do consumo } \\
\text { humano } \\
\end{array}$ & \\
\hline & $\begin{array}{c}\text { 1. Oficina - com os } \\
\text { animais de borracha } \\
\text { (animais representantes } \\
\text { de diferentes espécies } \\
\text { da fauna local) }\end{array}$ & $\begin{array}{l}\text { Reconhecer os } \\
\text { animais da } \\
\text { fauna local e } \\
\text { sua importância }\end{array}$ & $\begin{array}{l}\text { Os animais foram expostos numa } \\
\text { mesa e cada morador (a) escolhia, de } \\
\text { forma voluntária, quatro espécies de } \\
\text { animais diferentes, variando dos } \\
\text { vertebrados e invertebrados e depois } \\
\text { comentaram sobre sua importância e } \\
\text { benefícios para a sociedade e o meio } \\
\text { ambiente. }\end{array}$ \\
\hline \multirow[t]{2}{*}{$2^{\circ}$ dia } & $\begin{array}{l}3^{\text {a }} \text { Atividade: vídeo - } 3 \\
\text { "O ICMBio - } \\
\text { Biodiversidade } \\
\text { Brasileira". }\end{array}$ & $\begin{array}{c}\text { Conhecer a } \\
\text { biodiversidade } \\
\text { brasileira e } \\
\text { seus benefícios }\end{array}$ & $\begin{array}{l}\text { Durante a apresentação do vídeo } \\
\text { sobre a importância da biodiversidade } \\
\text { da fauna e flora foram sendo } \\
\text { esclarecidas dúvidas sobre o porquê } \\
\text { de cuidar do meio ambiente, dos } \\
\text { animais e das plantas para assim } \\
\text { evitar desequilíbrios ambientais e a } \\
\text { caça aos animais silvestres, prática } \\
\text { essa que pode causar impactos na } \\
\text { comunidade e no PNSC }\end{array}$ \\
\hline & $\begin{array}{l}\text { 20 Oficina - exposição } \\
\text { das imagens dos } \\
\text { animais vertebrados e } \\
\text { invertebrados, anfíbios, } \\
\text { mamíferos e aves. }\end{array}$ & $\begin{array}{c}\text { Separar os } \\
\text { diferentes } \\
\text { grupos animais }\end{array}$ & $\begin{array}{c}\text { Cada morador(a) escolhia uma } \\
\text { imagem do animal, falava sobre o seu } \\
\text { benefício e importância para o } \\
\text { equilíbrio ambiental e depois fixava no } \\
\text { cartaz. }\end{array}$ \\
\hline
\end{tabular}

Fonte: autoria própria (2019).

Destaca-se que as atividades foram realizadas e conduzidas baseadas no trabalho de Machado, Abílio e Holanda (2017) e Abílio, Andrade e Lacerda (2017). As atividades permitiram fortalecer mais o nível de confiança que se dá

Revbea, São Paulo, v.16, № 1: 527-547, 2021. 
numa relação entre o pesquisador e o pesquisado. Entretanto, os residentes, mesmo tendo sido convidados a participarem, foram um pouco reticentes durante as atividades de sensibilização que ocorreram no posto de atendimento médico da comunidade.

Dessa forma, as vivências na comunidade de Cachoeira buscaram estreitar o elo entre o pesquisador e os locais. A educomunicação caracterizase como um campo de intervenção de grupos sociais para ampliar a capacidade expressiva das pessoas, independentemente da condição social e grau de instrução (BRASIL, 2015). Assim, é uma ferramenta que aproxima as pessoas, aumentando a socialização, e segundo Berk et al. (2018, p.2), "[...] é uma ferramenta propulsora de informação e conhecimento" que atinge muitas pessoas. O mesmo autor salienta que o uso de vídeos, na EA, possibilita um conhecimento dos problemas relacionados com as pessoas envolvidas

A utilização de vídeos, assim como outras ferramentas, é "[...] importante [para a] criação de mecanismos que possibilitem identificar concepções de EA de livros, materiais didáticos, vídeos, filmes, programas de televisão, entre outros" (SILVA; KRASILCHIK, 2007, p.5). Ainda os autores salientam que para cada ideia é necessário levar em consideração alguns elementos fundamentais no processo educativo relacionado com a temática ambiental e que se tornam presentes quando da análise exploratória dos vídeos (SILVA; KRASILSHIK, 2007). Com a possibilidade de sensibilizar o sujeito, permitindo-lhe interagir diretamente, o vídeo pode gerar sentimentos, emoções perante os problemas ambientais e segue-se a transformação e mudança de atitudes, seja ela individual ou coletiva, com único propósito de preservação do meio ambiente.

No primeiro momento, houve a apresentação da $1^{\text {a }}$ Atividade: vídeo - 1 intitulado "Projeto Pró-Espécies como iniciativa do Ministério do Meio Ambiente em prol de espécies". Os moradores assistiram atentos ao vídeo e no final foi feita uma discussão com eles. Alguns falaram um pouco, mas a maioria ficou calada porque não estão habituados com este procedimento, mas aos poucos foram aumentando a participação em atividades subsequentes. Desse modo, eles viram as problemáticas e apontaram, através do diálogo (já estavam interagindo mais), as situações apresentadas no vídeo que eles tinham percebido no entorno do PNSC (Figura 2).

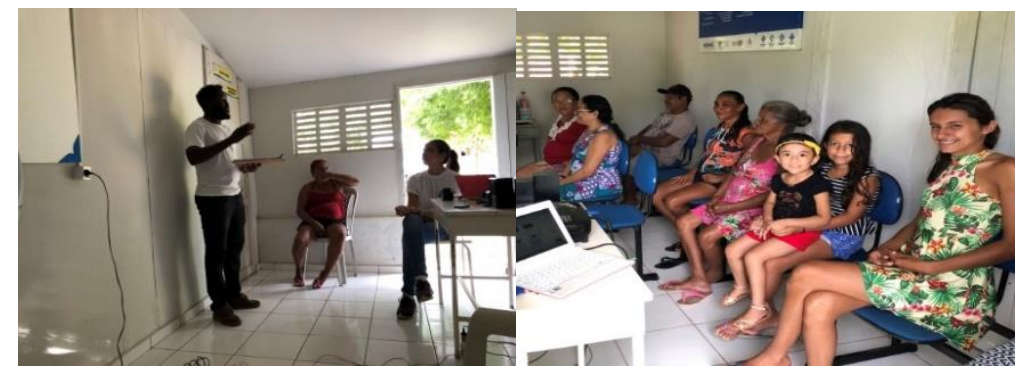

Figura 2: Realização de vivências com os moradores da comunidade Cachoeira - Município de Brasileira, PI Fonte: autoria própria (2019). 
Para Azevedo (2019), os vídeos são importantes ferramentas que contribuem fortemente para a divulgação de ações e mobilização social, no sentido de sensibilizar o indivíduo e conscientizar com causas ambientais, como foi utilizado nessa pesquisa.

Desse modo foi realizada a $2^{a}$ atividade: vídeo -2 , intitulado "MAN by Steven Cutts - 500,000 anos atrás". Os dois vídeos foram apresentados com o propósito de sensibilizar os moradores sobre os vícios de hiperconsumo acelerado do ser humano e as consequências da caça predadora e o desmatamento.

Muenchen e Delizoicov (2014) apontaram que as oficinas pedagógicas, como as utilizadas na pesquisa, foram baseadas na dinâmica conhecida como os Três Momentos Pedagógicos (3MP) que foram adaptadas para o meio rural e assim puderam ser utilizadas na EA não-formal, sendo estes a problematização inicial, organização e a aplicação do conhecimento.

As oficinas e as atividades foram abordadas de modo que os moradores pudessem se sentir sensibilizados com as questões que foram propostas e que se associavam ao cotidiano. Destarte o conhecimento assimilado poderá provocar uma mudança de atitude, seja ela coletiva, seja ela individual. A aplicação do conhecimento associado às questões ambientais foi propositada para provocar debates sobre as ameaças da fauna na zona do amortecimento da UC.

No segundo momento foi feita $1^{a}$ oficina com os animais de plástico (animais representantes de diferentes espécies da fauna local). Após ter escolhido os animais, cada participante teve a oportunidade de se expressar sobre eles e assim comentaram sobre o que sabiam da importância e benefícios para o ser humano e o meio ambiente. Alguns animais eram mais conhecidos, o que permitiu maior detalhamento de características, porém outros só eram conhecidos pelo nome (Figura 3).

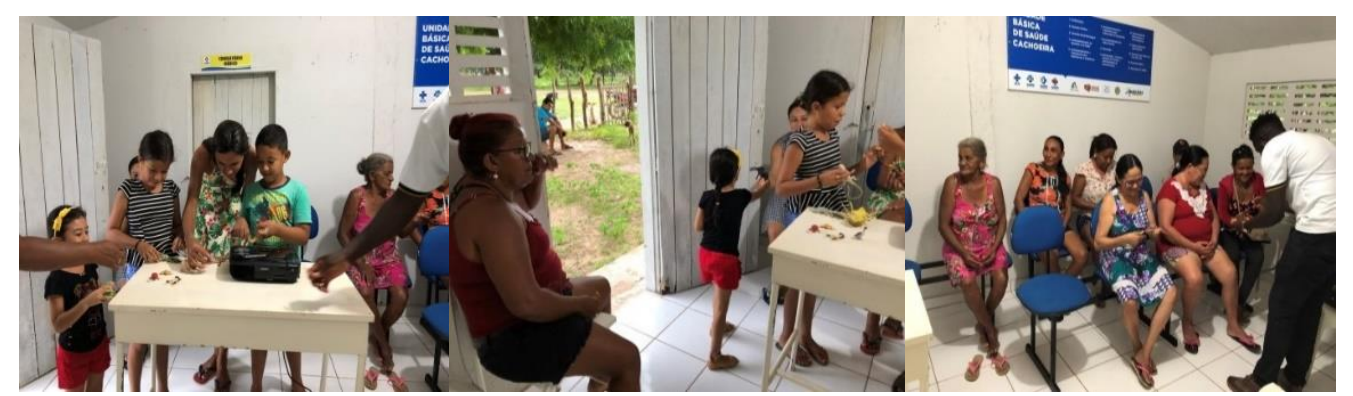

Figura 3: 1를 Oficina com os moradores da comunidade Cachoeira - Município de Brasileira, PI Fonte: autoria própria (2019).

Logo, essa abordagem sistemática do saber com a aplicação das oficinas com animais de plástico, a produção de cartazes e os vídeos didáticopedagógicos, permitiram aumentar a relação dos moradores com o meio no qual estavam inseridos a partir de ações educativas direcionadas. 
No segundo dia seguiu-se a continuidade da apresentação dos vídeos sobre os problemas ambientais com a 3" Atividade, vídeo intitulado "O ICMBio. - Biodiversidade Brasileira".

Durante a apresentação do vídeo, no segundo dia, falou-se sobre a importância da biodiversidade da fauna e flora e os moradores presentes tiveram a oportunidade de serem esclarecidos sobre os motivos para cuidar do meio ambiente, dos animais e das plantas para, assim, evitar desequilíbrios ambientais e a caça aos animais silvestres, que causa impactos na comunidade e no PNSC. Nesse momento foi possível perceber o pouco conhecimento sistematizado que os participantes tinham sobre a conservação da biodiversidade animal e/ou vegetal (Figura 4).

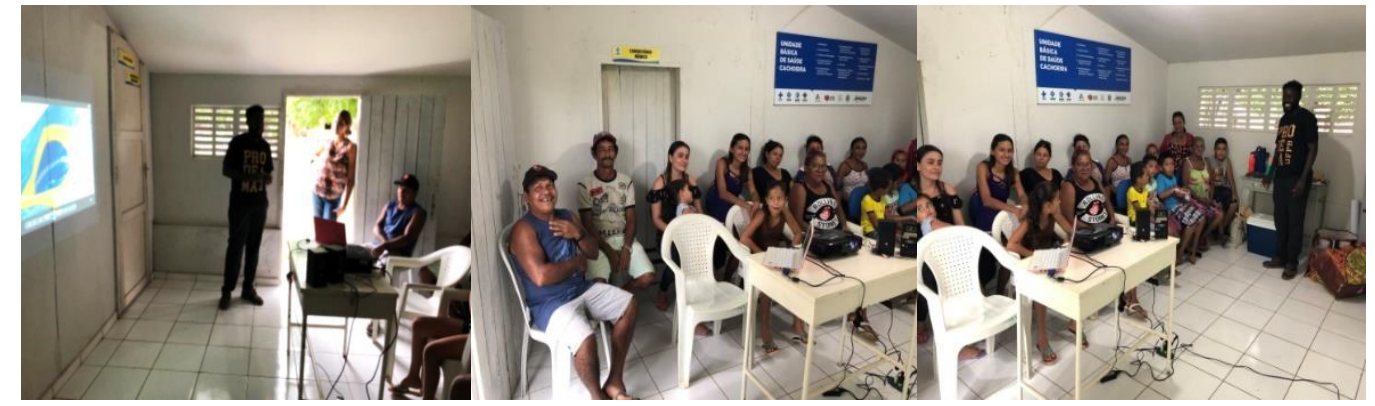

Figura 4: Apresentação de vídeo de sensibilização com os moradores da comunidade de Cachoeira - Município de Brasileira, PI.

Fonte: autoria própria (2019).

A utilização dos vídeos no processo de sensibilização gera impacto maior na sociedade, de acordo com Azevedo (2019), e a relevância para a conservação dos atrativos naturais e potencialidades turísticas e educativas são observadas. O uso do vídeo foi escolhido com o intuito de impactar os moradores da comunidade de Cachoeira.

Os impactos das ações de sensibilização através das oficinas e vídeos didáticos na EA são vistos como positivos, porém, não deixam de apresentar fragilidades. "Entretanto, ao planejar oficinas há de se ter cuidado para não considerar os caminhos como já construídos, soluções como já acabadas e definitivas e, sim, possibilitar um movimento sempre contínuo e renovador em busca do saber" (BERARDINELLI; SANTOS, 2007, p.397).

Os autores afirmaram que, primeiramente, é preciso tentar explorar a oficina, no sentido de compreender o ser humano, a forma de ser de cada um, suscitando reflexão a partir da identidade dos sujeitos (BERARDINELLI; SANTOS, 2007). O planejamento da oficina é algo imprescindível e convém destacar que tudo que foi elaborado num primeiro momento precisou ser reelaborado de acordo com a realidade dos moradores.

Para Da Silva e Leite (2008), as oficinas e vídeos que são incorporados no processo de sensibilização da EA, devem tornar a aprendizagem prazerosa 
e, nesse caso, a escolha das atividades deve favorecer o inter-relacionamento entre todos os membros que estão participando da ação.

Essas atividades atraíram muitas crianças porque os adultos perceberam que as crianças tinham curiosidade e interesse em participar. Foi proveitoso porque através das crianças pôde-se atingir o objetivo que era compartilhar a sensibilização de EA com mais pessoas da comunidade.

Entretanto, pode-se destacar a experiência encontrada no trabalho de Córdula (2015), quando o autor destacou a importância da participação de crianças em atividades de sensibilização, pois o público infantil geralmente é mais interativo e dinâmico neste tipo de processo de aprendizagem, pois apresentam mais curiosidades e uma disposição maior em aprender novos conteúdos. Os adultos, porém, criam uma certa resistência para participarem deste tipo de ação de sensibilização.

Com essas atividades teve-se o cuidado com os moradores da comunidade, de acordo com o que diz Morin (2006), que um dos principais objetivos da educação é cuidar do destino de cada um e de todos.

Por último foi feita a $2^{a}$ oficina, a exposição das imagens (fotografias) dos animais vertebrados e invertebrados, que contribuiu com a diferenciação dos animais e compreender como esses animais são nomeados pelos moradores da comunidade (Figura 5).

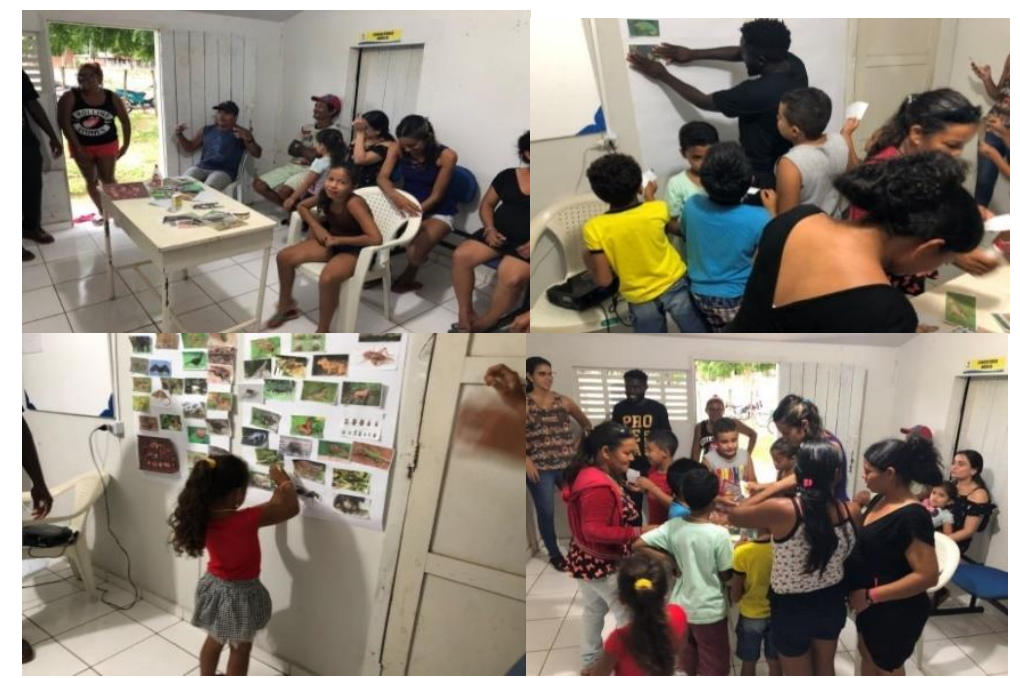

Figura 5: Realização das atividades de sensibilização dos moradores da comunidade Cachoeira - Município de Brasileira, PI.

Fonte: autoria própria (2019).

Nesse momento foi possível explorar o conhecimento prévio que eles tinham e ouvir as histórias sobre os animais que eram conhecidos e mais próximos de todos, trazendo o cotidiano para a discussão. Esta atividade foi muito dinâmica e interativa, onde os participantes escolhiam e identificavam uma espécie de animal nativa, seja ele vertebrado ou invertebrado. Caso não 
soubesse a resposta, os demais podiam ajudar a responder, dizendo o nome do animal, nome esse que era fixado num mural construído para esta atividade.

Para Santana e Moura (2012, p.101),

Entre as diversas formas de se promover a construção de saberes em Educação Ambiental crítica, a linguagem fotográfica se coloca como um instrumento de informações capaz de oferecer a aproximação com o lugar a ser analisado e, com isso, desenvolver sentimentos pela aproximação com a realidade.

Logo, a realização de oficina com fotografias visou sensibilizar e estimular a cultura fotográfica e a Percepção do Ambiente na qual o públicoalvo se encontra. Esta relação também foi apontada por Perinotto e Coelho (2012), que afirmaram a provocação da sensibilidade humana acima da imagem apresentada de forma propositada para criar sentimentos e compreensão dos problemas ambientais.

\section{Conclusão}

Esta pesquisa apontou que poucos moradores da comunidade de Cachoeira tinham consciência ambiental e a pesquisa contribuiu para aumentar essa consciência e fazer com que eles percebessem a possibilidade do uso responsável dos recursos naturais disponíveis. Espera-se que assim diminuase os possíveis impactos ambientais na região do PNSC, mesmo que tenham sido ofertadas poucas ações sensibilizadoras.

Com o intuito da transformação de consciência ambiental na zona de amortecimento do PNSC, iniciou-se um processo de sensibilização e aumento do acesso ao conhecimento sobre a fauna (os animais vertebrados e invertebrados) nativa da região, principalmente dos grupos de animais que são vistos como desnecessários por serem perigosos.

Destaca-se também sobre a importância da UC que, a princípio, não era compreendida pelos moradores da comunidade como local de riqueza biológica. O PNSC, muitas vezes, foi definido como "ali só tem mata". Durante as atividades foi possível perceber que os moradores passaram a compreender - PNSC como local com grande biodiversidade e que as riquezas da UC representavam algo novo.

Ao confrontar os problemas que ameaçam as riquezas biológicas e cênicas que existem na parte interna do Parque Nacional (PARNA), detectamos que a ineficiência por falta de recursos para implementação do plano de manejo que é o principal manual de gestão da UC, e como, também, a idealização através de abertura de novos editais para contratação de novos colaboradores (agentes ambientais que atuam dentro e fora da UC), com vista 
à execução das atividades de sensibilização através de projetos educativos de EA. No que diz respeito à fauna, a pesquisa contribuiu no sentido de discutir com os moradores sobre "os bichos" como os moradores nomeavam todos os animais, inclusive destacando que "não prestavam" por serem venenosos. Foram esclarecidos os equívocos identificados nas entrevistas realizadas.

As ações de sensibilização iniciadas junto aos moradores da comunidade de Cachoeira incorporaram a EA não-formal provocando mudança de atitudes dos indivíduos com menos grau de instrução. Isso não ocorre por esta ser uma ação sistemática ou conteúdo programado, mas por ser flexível e adaptável para atender as demandas do campo de acordo com o contexto investigado. As atividades foram prazerosas e interativas e possibilitaram a discussão sobre os diferentes animais dos grupos de vertebrados e invertebrados, possibilitando assim que o conhecimento dos moradores fosse ampliado e, nessa feição, espera-se que os impactos ambientais diminuídos e a biodiversidade animal sejam preservados.

\section{Agradecimentos}

À Coordenação de Aperfeiçoamento de Pessoal de Nível Superior Nacional (CAPES), pelo apoio financeiro à pesquisa; à Universidade Federal da Paraíba por tornar possível o mestrado do autor.

\section{Referências}

ABÍLIO, F. J. P. Educação Ambiental em unidade de conservação na caatinga paraibana: Práticas pedagógicas e formação continuada de professores. João Pessoa: Editora do CCTA, 2017. 321p.

ABÍLIO, F. J. P. Ética, cidadania e Educação Ambiental. In: ANDRADE, M. O. de (Org.). Meio Ambiente e desenvolvimento: bases para uma formação interdisciplinar. João Pessoa: Editora Universitária da UFPB, 2008. p. 325-349.

ABÍLIO, F. J. P. Educação Ambiental para Semiárido. João Pessoa: Editora Universitária da UFPB, 2011. 580p.

ALVES, E. R. de A.; SOUZA, G. da S.; MARRA, R. Êxodo e sua contribuição à urbanização de 1950 a 2010. Área de Informação da Sede-Artigo em periódico indexado (ALICE), Revista de política Agrícola, Brasília, ano 20, n. 2, pag. 80-88, abr./maio/jun./2011.

ANDRADE, M. C. de. O Nordeste e a questão regional. 2. ed. São Paulo: Ática, 1993. p.70.

AZEVEDO, A. A. Gestão socioambiental da Gruta do Salitre, Reserva da Biosfera da Serra do Espinhaço, sudeste do Brasil. In: ZAMPAULO, R. A. (Org.) CONGRESSO BRASILEIRO DE ESPELEOLOGIA, 35, 2019. Bonito. Anais [...] Campinas: SBE, 2019. p.278-283. Disponível em: $<$ http://www.cavernas.org.br/anais35cbe/35cbe 278-283.pdf >. Acesso em: 06 dez. 2019. 
BARDIN, L. Análise de conteúdo. 3. reimpr.1. ed. São Paulo: Edições 70, 2016.

BERARDINELLI, L. M. M.; SANTOS, M. L.S. C. Oficina pedagógica de enfermagem: uma experiência da convergência cuidado-educação. Revista Gaúcha de Enfermagem. v. 28, n. 3, n. 430-8, 2007.

BERK, A.; DA MATTA, R.; ROCHA, M. B.; RAMOS, A.; QUEIROY, L.; LISBOA, R. A produção de documentários ambientais sobre o parque nacional da tijuca: uma experiência de estudantes da graduação. Rio de Janeiro: Ciência em Tela. v.11, n.2- 2018.

BRASIL. Decreto no 50.744, de 8 de junho de 1961. Cria o Parque Nacional de Sete Cidades, integrante da Seção de Parques e Florestas Nacionais do Serviço Florestal, do Ministério da Agricultura.

BRASIL. Lei $n^{0}$ 9.985, de 18 de julho de 2000. Mensagem de Veto Regulamenta o art. 225, § 1을 incisos I, II, III e VII da Constituição Federal, institui o Sistema Nacional de Unidades de Conservação da Natureza e dá outras providências. Diário Oficial da República Federativa Brasil, Brasília, DF, 19 dez. $2000 . \quad$ Disponível em: <http://www.mma.gov.br/estruturas/240/ arquivos/snuc 240.pdf>. Acesso em: 23 out. 2018.

BRASIL. Ministério do Meio Ambiente. Série Educação Ambiental e Comunicação em Unidades de Conservação. Brasília: MMA, 07. out. 2015. Disponível em: <https://www.mma.gov.br/publicacoes/educacaoambiental/category/154-serie-ea-uc>. Acesso em: 09 nov. 2019.

CÓRDULA, E. B. L. Educação Ambiental e sensibilização para conservação dos recursos naturais em um assentamento agrícola em Lucena-PB. 2015. 198f. Dissertação (Mestrado em Desenvolvimento e Meio Ambiente) Programa de Pós-Graduação em Desenvolvimento e Meio Ambiente PRODEMA, Universidade federal da Paraíba, João Pessoa, 2015.

COSTA NETO, E. M. Os insetos que ofendem: Artrópodes na visão dos moradores da região da Serra da Jibóia, Bahia, Brasil. Sitientibus, Série Ciências Biológicas, v. 4, n.1/2, n. 59-68, 2004.

DA SILVA, M. M. P.; LEITE, V. D. Estratégias para realização de Educação Ambiental em escolas do ensino fundamental. Revista Eletrônica do Mestrado em Educação Ambiental. Porto Alegre, RS. v. 20, 2008.

DE SOUSA, J. D.; L.; D. C.; DA SILVA BRITO, F. C.; DE MEDEIROS, A. P.; DE PAIVA, A. C. C.; MARACAJA, P. B. O desenvolvimento da região nordeste: uma abordagem econômica e ambiental. Rev. Eletrônica Mestr. Educ. Ambient., v. 11, n. 1, p. 42-48, 2017.

FAVERA, J. C.D. Parque Nacional de Sete Cidades, PI: magnífico monumento natural. Sítios geológicos e paleontológicos no Brasil, v. 1, 2002, p.335342. 
GALLO, D.; NAKANO, O.; SILVEIRA NETO, S.; CARVALHO, R. P. L.; BATISTA, G. C.; BERTI FILHO, E.; PARRA, J. R. P.; ZUCCHI, R. A.; ALVES, S. B.; VENDRAMIN, J. D.; MARCHINI, L. C.; LOPES, J. R. S.; OMOTO, C. Entomologia agrícola. Piracicaba: FEALQ, 2002.

ICMBio. - Instituto Chico Mendes de Conservação da Biodiversidade / MMA Ministério do Meio Ambiente. Livro Vermelho da Fauna Brasileira Ameaçada de Extinção: Volume III - Aves / -- 1. ed.-- Brasília, DF: ICMBio/MMA, 2018.7 v. : il.

LAKATOS, E. M.; MARCONI, M. A. Fundamentos de metodologia cientifica. 7. ed. São Paulo: Atlas, 2010.

LIMA, S. S.; LEITE, L. F. C.; OLIVEIRA, F. C.; COSTA, D. B. Atributos químicos e estoques de carbono e nitrogênio em argissolo vermelho-amarelo sob sistemas agroflorestais e agricultura de corte e queima no norte do Piauí. Revista Arvore, v. 35, p. 51-60, 2011.

MACHADO, M. G.; ABÍLIO, F. J. P. Educação Ambiental contextualizada para a Educação de Jovens e Adultos no bioma Caatinga: vivências pedagógicas em uma escola pública do Cariri Paraibano. REMEA - Revista Eletrônica do Mestrado em Educação Ambiental, [S. I.], v. 34, n. 1, p. 127-147, 2017.

MELAZO, G. C. Percepção Ambiental e Educação Ambiental: uma reflexão sobre as relações interpessoais e ambientais no espaço urbano. Uberlândia: Olhares e Trilhas. Ano VI, n. 6, p. 45-51, 2005.

MORIN, E. Os Sete Saberes necessários à Educação do Futuro. 11. ed. São Paulo: Cortez, UNESCO, 2006.

MUENCHEN, C.; DELIZOICOV, D. Os três momentos pedagógicos e o contexto de produção do livro "Física". Ciênc. educ. (Bauru), Bauru, v. 20, n. 3, p. 617-638, Set. 2014.

PALMA, I. R. Análise da percepção ambiental como instrumento ao planejamento da Educação Ambiental. 83 folhas. Tese Dissertação (Mestrado em Engenharias) - Universidade Federal de Rio Grande de Sul. Porta Alegre. 2005.

PEREIRA, C. C.; SILVA, F. K.; RICKEN, I.; MARCOMIN, F. E. Percepção e Sensibilização Ambiental como instrumentos à Educação Ambiental \&lt;BR\&gt; Perception and awareness as tools for Environmental Education. REMEA Revista Eletrônica do Mestrado em Educação Ambiental, [S. I.], v. 30, n. 2, p. 86-106, 2014.

PERINOTTO, A. R. C.; COÊLHO, H. F. C. Educação e fotografia: Uma análise quantitativa do projeto" olhar socioambiental". Educação: Teoria e Prática, v. 22, n. 41, p. 61-81, 2012.

RICHARDSON, R. J.; PIRES, J. A. S.; WANDERLEY, J. C. V.; MARTINS, L. C.; PIRES, M. H. M. et al. Pesquisa social: Métodos e Técnicas. 3. ed. 11. reimpr. São Paulo: Atlas, 2010. 
ROHDE, G. M. A origem geológica das formações rochosas de Sete Cidades. Boletim Geográfico do Rio Grande do Sul, n. 19, p. 51-61, 2014.

SANTANA, D. A.; MOURA, J. D. P. A fotografia como instrumento para a consciência socioambiental. JORNADA DE DIDÁTICA-O ENSINO COMO FOCO E FÓRUM DE PROFESSORES DE DIDÁTICA DO ESTADO DO PARANÁ, 1. 2012. Anais [...] Londrina: UEL, 2012.

SATO, M. Apaixonadamente pesquisadora em Educação Ambiental. Educação Teoria e Prática, Rio Claro, v. 9, n. 16/17, p. 24-35, 2001.

SAUVÉ, L. Uma cartografia das correntes de Educação Ambiental. In: SATO M.; CARVALHO I. C. M. (Orgs.). Educação Ambiental: pesquisas e desafios. Porto Alegre: Artmed, p. 17-44. 2005.

SILVA, R. L. F.; KRASILSHIK, M. Dimensão ética e política de filmes didáticos de meio ambiente: um estudo com a programação da TV Escola. ENCONTRO DE PESQUISA EM EDUCAÇÃO AMBIENTAL, 4., Rio Claro. Anais [...] Rio Claro: EPEA, 2007.

TAMAIO, I. O professor na construção do conceito de natureza: uma experiência de Educação Ambiental. São Paulo: Annablume, 2002.

TEIXEIRA FILHO, N. P. Tradições e Transformações Culturais: o aumento do consumo de insetos pelo ocidente. In: TOLEDO, F dos S. (org.) Meio Ambiente em Foco. v.7 Belo Horizonte: Poisson, 2019, p.58-68. 